\title{
Studies on the male and female copulatory apparatus of Trichuris globulosa (Nematoda, Trichuridae)
}

\author{
H. KAUR ${ }^{1}$, C. L. DUGGAL ${ }^{2}$ \\ ${ }^{1}$ Department of Zoology, Punjabi University, Patiala - 147002, Punjab, India, E-mail: harpreet_bimbra@yahoo.com; \\ ${ }^{2}$ Department of Zoology, Panjab University, Chandigarh - 160014, India
}

\begin{abstract}
Summary
The process of copulation in Trichuris globulosa (see Linstow, 1901) Ransom, 1911 has been studied using morphological, histological and scanning electron microscopical techniques (Keilley et al., 1973). The ventral coiling of the posterior part of the male body around the female is achieved by specialized muscles of the ventral body-wall. The single simple pointed spicule emerges with the everting cirrus and acquires a J-shape. The spicule may help in keeping apart the cuticular brim of the non-spiny noneversible part of the vagina during insemination. The cloacal tube is long with a detached internal cuticle which is eversible to the outside as a cirrus. Eversion is brought about by the protrusion of the spicule and contraction of the muscles of the spicule pouch. During eversion part of the proximal cloacal tube is also extruded and forms the globular part of the cirrus. The globular part is covered with spines, which may help in retaining the male and female in copula. The vagina is differentiated into the proximal vagina uterine and distal vagina vera. The vagina vera has a distal eversible spiny part and a proximal noneversible unarmed part. In Trichuris globulosa, the vagina vera is shorter than the spicule.
\end{abstract}

Key words: nematode; copulation; spicule; cirrus; trichuroid

\section{Introduction}

Formerly, the spicules of most nematodes were considered to open the female gonopore for copulation, however, electron microscopic studies on the spicules of Heterodera spp. (Clark et al., 1973), Nippostrongylus brasiliensis (see Travassos, 1914; Croll \& Wright, 1976), Pratylenchus penetrans (see Cobb, 1917; Hogger \& Bird, 1974) Panagrellus redivivus (see Linnaeus, 1767; Duggal, 1978) and Oesophagostomum columbianum (see Curtice, 1890; Duggal \& Kaur, 2006) have shown that spicules form an en- closed tubular structure through which sperm passes into the female.

One or more pores have been found at the tip of each spicule in Heterakis gallinarum (see Schrank, 1788; Lee, 1973), Pratylenchus penetrans (see Cobb, 1917; Wen \& Chen, 1976), Aphelenchoides blastophthorus (see Franklin 1952; Clark \& Shepherd, 1977), Panagrellus redivivus (see Linnaeus, 1767; Duggal, 1978), Calodium hepaticum (= Capillaria hepatica) (see Bancroft, 1893), Trichuris muris (see Schrank, 1788; Wright, 1978), and Ascaridia galli (see Schrank, 1788; Duggal \& Kaur, 2000). The presence of nerve endings beneath these pores suggested a chemosensory function. The caudal papillae are reported to have a central nerve process opening to the exterior, suggesting a chemosensory function in addition to their possible mecha-nosensory function (McLaren, 1976; Dick \& Wright, 1974; Wagner \& Seitz, 1982).

Wright (1978) found no sensory papillae in the cloacal region of Trichuris muris but found that protrusion of the spicule and cirrus took place on mechanical stimulation in the distal cloacal region.

Here, the posterior region of male and the vaginal region of female Trichuris globulosa were examined by light microscope and scanning electron microscopy. Their functional importance during copulation is discussed.

\section{Material and Methods}

Males and females of Trichuris globulosa, (see Linstow, 1901) Ransom, 1911 from the intestines of sheep and goats were fixed at $4{ }^{\circ} \mathrm{C}$ in $4 \%$ glutaraldehyde in cacodylate buffer at pH 7.2 for $4 \mathrm{hrs}$ (Keilley et al., 1973). They were post-fixed in $1 \%$ osmium tetra oxide for $3-4 \mathrm{hrs}$ at $4{ }^{\circ} \mathrm{C}$ in cacodylate buffer, rinsed in buffer for 5-10 times, and incubated in fresh $1 \%$ aqueous, saturated filtered thiocarbohydrazide $(\mathrm{TCH})$ for $10 \mathrm{~min}$ at $25{ }^{\circ} \mathrm{C}$. After thorough washing in distilled water, specimens were dehydrated 
through an acetone series to amyl acetate, dried in a critical-point drier and mounted on stubs for gold coating. They were examined in an EM 1200 Ex Jeol electron microscope.

For histological studies, specimens were fixed in Bouin and Carnoy fixatives and embedded in paraffin wax.

\section{Results}

\section{Male}

The male copulatory apparatus in Trichuris globulosa consists of ventral body-wall muscles, a spicule, a spicule pouch and a cloacal tube. The copulatory muscles are absent; however, body-wall muscles are better developed, ventrally.

The spicule is single, pointed and on eversion, acquires a Jshape (Fig. 1). SEM studies did not show any pore on the tip of the spicule. However, light microscopic studies showed that the cytoplasmic core extended up to the tip. The cloacal tube is formed by the union of the vas deferens with the intestine dorsally. It is a long tube and is further differentiated into proximal and distal regions. The cloacal tube is internally lined with cuticle, however, in Trichuris the cuticular lining is detached from the underlying epithelium to form an internal cuticular tube through most of its length (Figs. 12, 13) except in the anterior part of the proximal cloacal tube where it is firmly attached to the underlying epithelium.

The spicule pouch is single and it joins the cloacal tube on its ventral surface in the middle of the cloacal tube, dividing the cloacal tube into proximal and distal parts. The detached tubular cuticular lining of the distal cloacal tube joins posteriorly with the body-wall cuticle and is armed with anteriorly-directed spines through most of its length, except near its junction with the spicule. The spicule penetrates and attaches to the internal detached tubular cuticular lining of the cloacal tube at the site where the spicule pouch joins the cloacal tube; proximally, it is attached to the spicule pouch. The retractor muscle is single but very long, extending to the proximal end of the vas deferens.
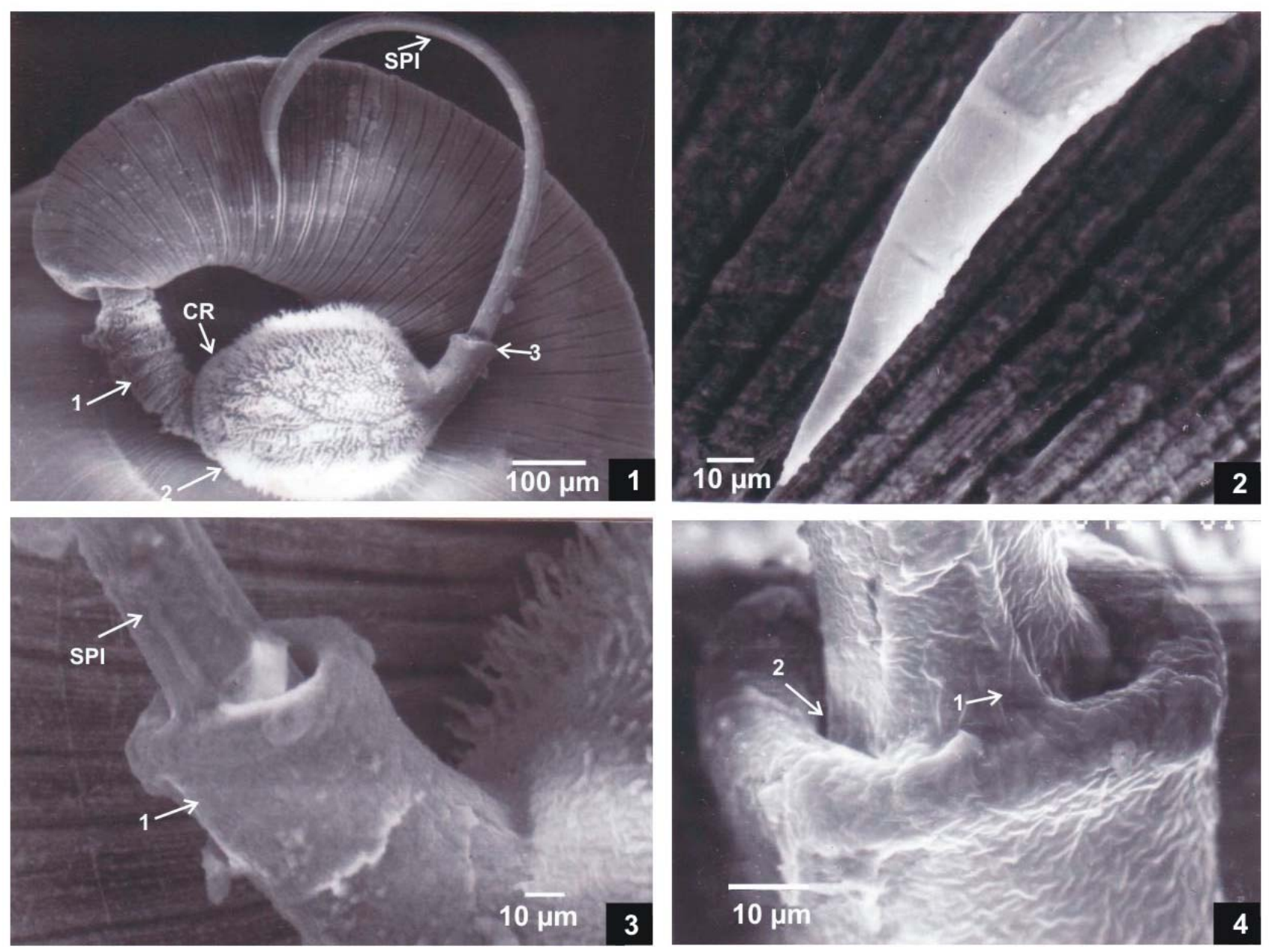

Fig. 1. Posterior part of Trichuris globulosa male showing fully everted cirrus (CR), having cylindrical proximal part $\left(\uparrow_{1}\right)$ and globular distal part $\left(\uparrow_{2}\right)$ with J-shaped spicule (SPI) surrounded by a collar - like outgrowth at its base $\left(\uparrow_{3}\right)$. (SEM); Fig. 2. Spicule tip (magnified). (SEM); Fig.3. Distal part of the globular cirrus showing non-spiny collar-like outgrowth at the base $\left(\uparrow_{1}\right)$ of the spicule (SPI). (SEM); Fig. 4. Collar-like outgrowth showing its attachment with spicule on its one side only $\left(\uparrow_{1}\right)$ leaving a crescent-shaped opening $\left(\uparrow_{2}\right)$. (SEM); $\mathrm{CR}=$ Cirrus, $\mathrm{SPI}=$ Spicule, $\mathrm{SP}=$ Spine 

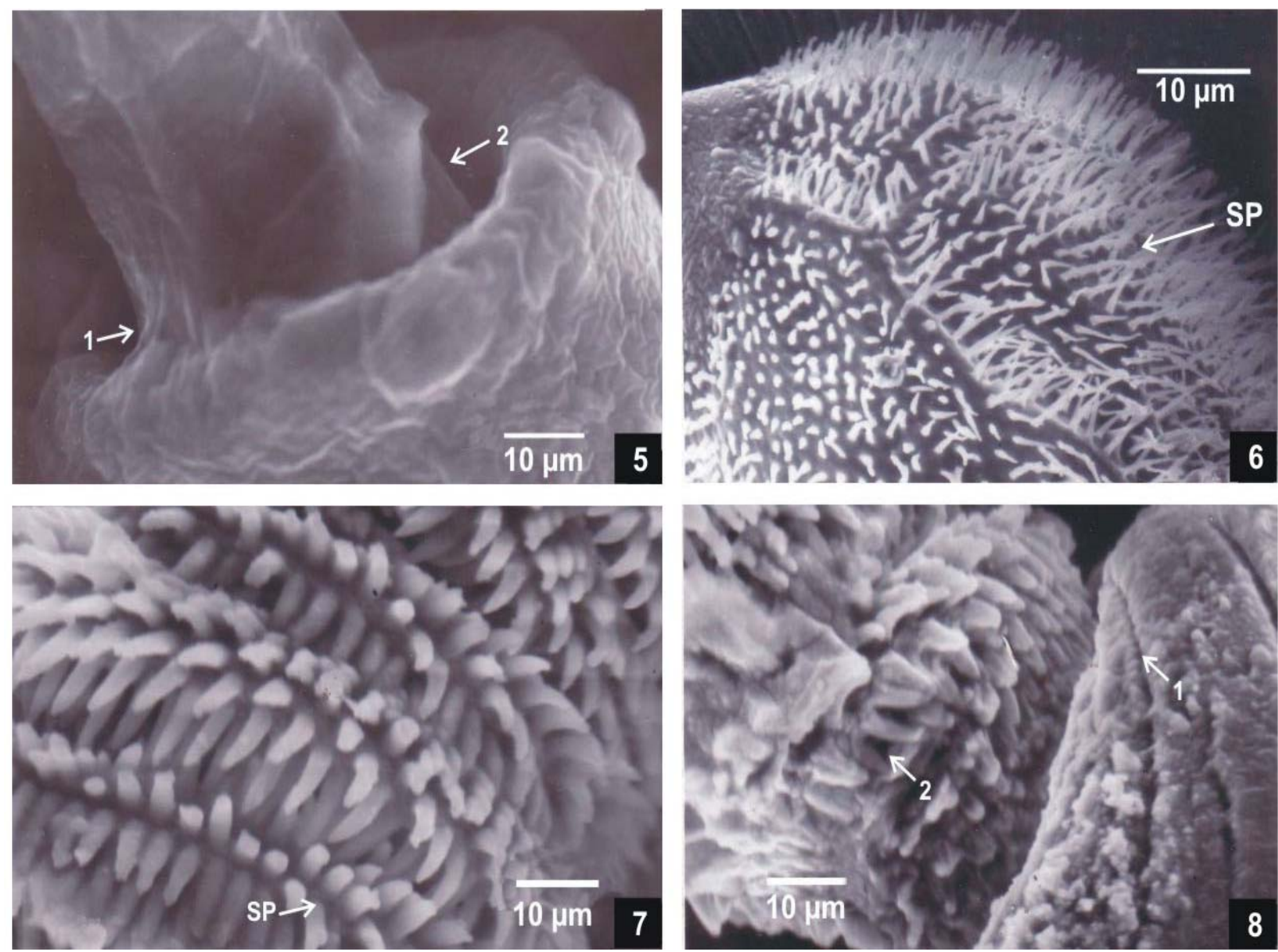

Fig. 5. Another view showing attachment of collar-like outgrowth on one side of the spicule $\left(\uparrow_{1}\right)$ leaving a crescent-shaped opening for the spermatozoa to come out $\left(\uparrow_{2}\right)$. (SEM); Fig. 6. Globular part of the everted cirrus with small spines on it (SP). (SEM); Fig.7. Cylindrical proximal part of the everted cirrus showing long, thick, circularly arranged spines (SP). (SEM); Fig.8. Tip of the male $\left(\uparrow_{1}\right)$ showing the protruding cirrus (no papillae) $\left(\uparrow_{2}\right) .(\mathrm{SEM})$;

$\mathrm{CR}=$ Cirrus, SPI $=$ Spicule, $\mathrm{SP}=$ Spine

The contraction of the protractor muscle sheath around the spicule pouch leads to protrusion of the spicule and the eversion of the internal detached tubular cuticle of the distal cloacal tube as a cirrus. In the fully everted cirrus, its proximal part, which measures $320-380 \mu \mathrm{m}$ when contracted and $560-720 \mu \mathrm{m}$ when extended, remains narrow and cylindrical whereas its distal part forms a globular expansion $490-520 \mu \mathrm{m}$ in diameter with a $110-160 \mu \mathrm{m}$ long collar at its distal end (Figs. 1, 3). From the centre of the collar arises a J-shaped spicule $1024-2032 \mu \mathrm{m}$ long (Fig. 1). The proximal cylindrical part and globular distal parts are armed with backwardly-directed spines (Figs. 1, $6,7,8$ ), the distal end and collar are unarmed (Fig.3). On the globular part, the spines are thin and small (Fig. 6), whereas on the proximal part they are thick, long and are arranged in circles (Fig. 7). In the collar, the spicule is attached on one side only, leaving a crescent-shaped opening for the sperm to emerge (Figs. 3, 4, 5). The globular expansion also encloses the posterior part of the tubular lining of the proximal cloacal tube, which by light microscopy is seen as a sac containing sperm ready for ejaculation (visble only in live specimens).

Histologically, the cloacal tube in Trichuris globulosa varies in structure. Proximally, it consists of tufted columnar epithelial cells, an inner circular muscle layer $32-34$ $\mu \mathrm{m}$ thick and a longitudinal muscle layer $2-4 \mu \mathrm{m}$ thick. In the anterior part of the proximal cloacal tube the cuticle is double layered and is firmly attached to the underlying epithelial cells whereas in the posterior part of the proximal cloacal tube the cuticle is also double layered but is loose from the underlying epithelial cells and forms a free tube in its lumen (Fig. 13). The distal cloacal tube consists of a thick epithelial layer with only a longitudinal muscle fibre sheath $46-52 \mu \mathrm{m}$ thick (Fig. 12). The epithelial layer itself is dense, contains numerous radial strands and is internally covered with a thin layer of cuticle. In addition to this cuticle, the lumen of the distal cloacal tube also encloses another detached spiny cuticular tube which is in continuation with similar tube in the proximal part, posteriorly it joins the body wall cuticle.

The spicule pouch is surrounded by a protractor muscle sheath is $58-90 \mu \mathrm{m}$ thick with similar histological characteristics as those of the distal cloacal tube, except that the lumen does not enclose an internal detached cuticular tube (Fig. 11). Caudal papillae are completely absent in Trichuris globulosa. 

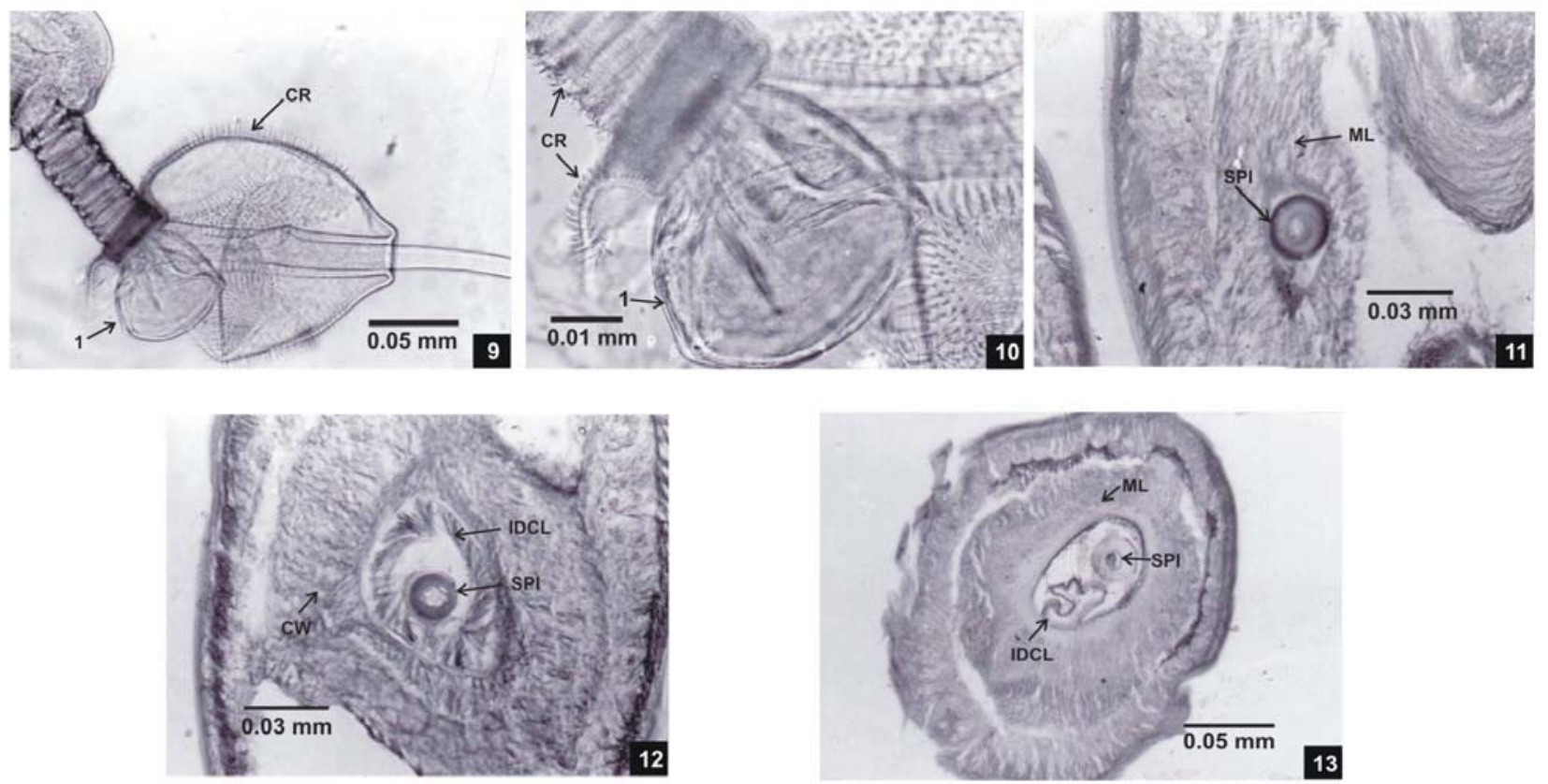

Fig. 9. Posterior end of $T$. globulosa male showing everted cirrus (CR) (mounted in saline, cirrus ruptured on lower side $\left(\uparrow_{1}\right)$;

Fig. 10. Globular part of the cirrus (CR) showing a sac formed by the detached internal cuticular lining ( $\left.\uparrow_{1}\right)$; Fig. 11. T.S. of spicular pouch showing centrally located spicule (SPI) surrounded by thick layer of longitudinal muscles (ML) (Bouins/MBPB); Fig. 12. T.S. of posterior part of the distal cloacal tube showing centrally placed spicule (SPI) surrounded by inner detached thin spiny cuticular lining (IDCL) and outer thick distal cloacal wall (CW) (Bouins/MBPB); Fig. 13. T.S. of posterior part of the proximal cloacal tube showing internal cuticular lining (IDCU) detached from its epithelium. (Bouins/Iron haematoxylin).

$\mathrm{CR}=$ Cirrus, $\mathrm{CW}=$ Cloacal wall, $\mathrm{IDCU}=$ Internal detached cuticle, $\mathrm{ML}=$ Muscle layer, $\mathrm{SPI}=$ Spicule.

\section{Female}

Vagina is differentiated into a convoluted proximal vagina uterina $600-700 \mu \mathrm{m}$ long and a distal vagina vera. Histologically, the wall of the vagina uterina consists of epithelial cells, club-shaped with narrow neck and bulbous tip measuring $19-19.6 \times 7-8 \mu \mathrm{m}$ (Fig. 17) and a circular muscle layer $38-48 \mu \mathrm{m}$ thick. The vagina vera is differentiated into a distal spiny eversible part $720-800 \mu \mathrm{m}$ long, and a proximal non-spiny non-eversible part $800-880 \mu \mathrm{m}$ long. The internal cuticle of the non-spiny non-eversible part of the vagina vera is very thick with a brim-like structure at its distal end and a very narrow lumen. The epithelium of the spiny part is thick and syncytial (Fig. 19), enclosing oval nuclei. That of the non-spiny part is cellular, with club-shaped cells and is lined with cuticle, $40-48$ $\mu \mathrm{m}$ thick (Fig. 18). The internal cuticle of the eversible part of the vagina vera is armed with many anteriorlydirected spines $5-8 \mu \mathrm{m}$ long spines (Figs. 15, 16, 19). The wall has a circular muscle layer $520-550 \mu \mathrm{m}$ thick and oblique muscles are present externally to this.

\section{Discussion}

Trichuris globulosa has a single spicule pointed at the tip which emerges with the everting cirrus. Wright (1978) also observed similar type of spicule and cirrus in Calodium hepatica and Trichuris muris. The present study indicate that the spicule acquires a J-shape when fully everted and such a shape may be helpful in keeping the cuticular brim of the non-spiny non-eversible part of the vagina about so that the sperm can be easily transferred to the proximal part of the vagina. In Heterodra spp. (Hogger \& Bird, 1974), Ascaridia galli (Duggal \& Kaur, 2000) and Oesophagostomum columbianum (Duggal \& Kaur, 2006) two equal spicules each with a pair of hard sclerotized alae on protrusion form a complete tubular structure through which sperm pass during copulation.

In this nematode, the cloacal tube is long and is further differentiated into proximal and distal regions by the joining of the spicule pouch to it. The cloacal tube is internally provided with a detached cuticular tube which joins posteriorly with the body wall cuticle at cloacal opening and is internally provided with anteriorly directed spines through most of its length. Similar observations have also been made by Wright, 1978 in C. hepatica and T. muris.

The present study indicate that the spicule enter into and fuses with the internal detached cuticular tube at the site where spicule pouch joins the cloacal tube, the contraction of the protractor muscle sheath present around the spicule pouch of Trichuris globulosa leads to the eversion of the internal detached cuticular tube at the site where spicule pouch joins the cloacal tube, the contraction of the protractor muscle sheath present around the spicule pouch of Trichuris globulosa leads to the eversion of the internal detached spiny cuticular tube of the distal part of cirrus along with the protrusion of the spicule. As the internal detached cuticular tube of the entire cloacal tube is a continuous one, the eversion of its distal spiny part as cirrus leads to the pulling of its proximal part and in the fully everted cirrus, the proximal detached cuticular tube 

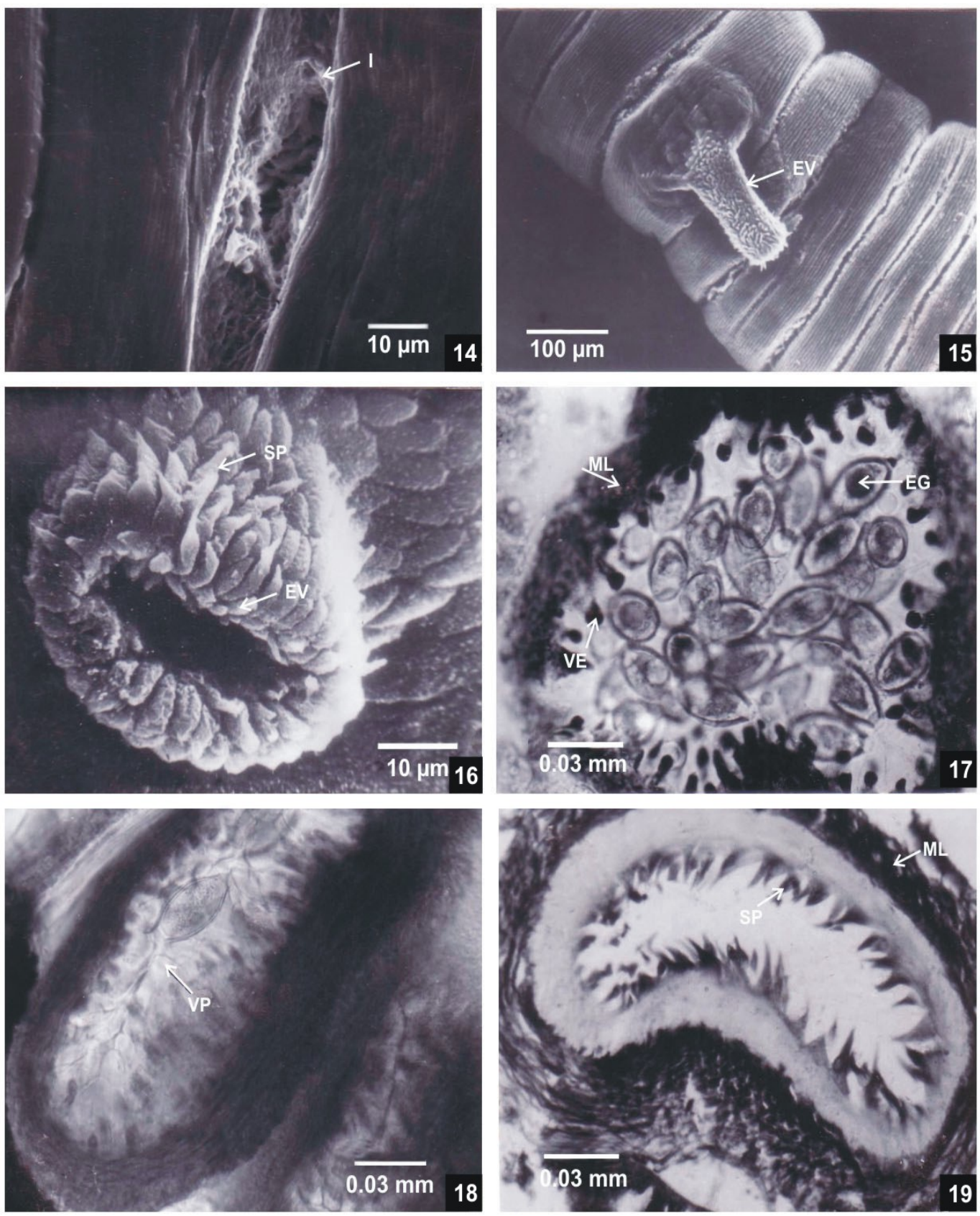

Fig. 14. Vulval opening of $T$. globulosa. Female showing fully retracted spiny part of the vagina vera $\left(\uparrow_{1}\right)$. (SEM); Fig. 15 . Ventral view of fully everted spiny part of the vagina (EV). (SEM); Fig. 16. Surface view of vulval opening (VO) with everted vagina ver (EV). (SEM) $\left(\uparrow_{1}\right)$;

Fig. 17. T.S. of vagina uterina showing club-shaped epithelial cells (VEP) surrounded by muscles (ML) Frozen cryostat/SDHase; Fig. 18. T.S. of vagina uterina showing thick cuticular internal linking in the form of plates (VP) $\left(\uparrow_{1}\right)$ Frozen cryostat/SDHase; Fig. 19. T.S. of distal vagina vera showing flattened epithelium having thick spiny cuticular layer at its luminal surface (SP), externally covered by circular muscle layer (ML). Bouins/Iron haematoxylin.

$\mathrm{EV}=$ Everted spiny part of vagina, $\mathrm{SP}=$ Spiny cuticular layer, $\mathrm{ML}=$ Muscle layer, $\mathrm{VEP}=$ Vaginal epithelium, $\mathrm{VO}=\mathrm{Vulval}$ opening, $\mathrm{VP}=$ Vaginal plates

extends up to the base of the protruding spicule in the globular part of the everted cirrus. Since the spicule is fused with the internal detached cuticular tube on its one side only, the spicule leaves around itself a crescent-shape opening through which the sperm come out at the time of ejaculation and in the fully everted cirrus this crescentshaped opening is located at the base of the protruding spicule on the globular part of the everted cirrus.
In many nematodes (Chitwood \& Chitwood, 1950; Lee \& Atkinson, 1976) the ventral coiling of the male tail is brought about by the contraction of the V-shaped copulatory muscles present on the ventro-lateral sides of the posterior part of the male body. The posterior part of the Trichuris globulosa male is also ventrally super-coiled although V-shaped copulatory muscles are absent. The present histological studies of the Trichuris globulosa 
indicate that in this species the body wall muscles are better developed on the ventral side of the posterior part of the male body and perhaps contraction of these body wall muscles bring about the ventral coiling, furthermore, the heavy musculature of extra long cloacal tube may also be helpful in coiling.

\section{References}

BANCROFT, T. L. (1893): On the whipworm of the rat's liver. J. and Proc. Roy. Soc., 27: 86 - 90

Chitwood, B.G., Chitwood, M.B. (1950): An Introduction to Nematology. Monumental Printing Company, Baltimore

Clark, S. A., ShePherd, A. M. (1977): Structure of the spicules and caudal sensory equipment in the male of Aphelenchoides blastophthorus (Nematoda: Tylenchida, Aphelenchina), Nematologica, 23: $103-111$

Clark, S. A., Shepherd, A. H., Kempton, A. (1973): Spicule structure in some Heterodera spp. Nematologica, 19: $242-247$

CoBB, N. A. (1917): A new parasitic nematode found infecting cotton and potatoes. J. Agr. Res., 11(1): $27-33$

Croll, N. A., Wright, K. A. (1976): Observations on the movement and structure of the bursa of Nippostrongylus brasiliensis and Nematospiroides dubius.Can. J. Zool., 54: $66-1480$

CurTice, C. (1890): The Animal Parasites of Sheep. Washington

DICK, T. A., Wright, K. A. (1974): The ultrastructure of the cuticle of the nematode Syphacia obvelata (Rudolphi, 1802). III. Cuticle associated with the male reproductive structures. Can. J. Zool., 52: $179-182$

DugGal, C. L. (1978): Copulatory behaviour of male Panagrellus redivivus. Nematologica, 24: $257-268$

DugGaL, C. L., KAUR, H. (2000): On the functional morphology of the copulatory apparatus of Ascaridia galli. J. Punj. Acad. Sci., 2 (1): 161 - 163

DugGal, C. L., KAUR, H. (2006): SEM studies on the copulatory apparatus of Oesophagostomum columbianum Helminthologia, 43: 3-5

FRANKLIN, M. T. (1952): A disease of Scabiosa caucasica caused by the nematode Aphelenchoides blastophthous $\mathrm{n}$. sp. Ann. Appl. Biol., 39: $54-60$

HogGer, C. H., BIRD, G. W. (1974): Secondary male sex characteristics of Hoplolaimus galeatus. J. Nematol., 6: 12 $-16$

Keilley, R. O., DekKer, R. A., Bluemink, J. G. (1973): Ligand mediated osmium binding: its application in coating biological specimens for SEM. J. Ultrastruct. Res., 45: $254-258$

LEE, D. L. (1973): Evidence for a sensory function for the copulatory spicules of nematodes. J. Zool., 169(3): $281-$ 285

LeE, D. L., AtKinson, H. J. (1976): Nematode sense organs. In B. DAwes (Ed.): Advances in Parasitology, 14, Academic Press, London \& New York, pp. 195 - 265

LinNAEUS, C. (1767): Systema naturae per regna tria naturae, Secundum classes ordines, genera, species cum characteribus, differentiis synomymis, locis. Editio duodecima, reformata. Holmiae (Stockholm), L. Salvii, pp. $533-1327$

LINSTOW, O. VON (1901): Helminthen von den Ufern des Nyassa Sees, ein Beitrag zur Helminthen-fauna von SüdAfrika. Jenaishe Ztschr. F. Naturw., 35, n.f. 28: 409 - 428 MCLAREN, D. J. (1976): Nematode sense organs. In Advances in Parasitology (ed. Ben Dawes) Vol. 14, Academic Press, London \& New York, pp. 195 - 265

Ransom, B. H. (1911): The nematodes parasitic in the alimentary tract of cattle, sheep and other ruminants. U.S. Dept. Agric. Bureau. Ani. Ind. Bull., 127, pp. 132

SCHRANK, F. P. (1788): Verzeichniss der bischer hinlanglich bekannten Eingeweidewuzmer, nebst einer Abhandwing uber ihre Anverwandtschaften, Muchen, pp. 116 TRAVASSOS, L. (1914): Trichostrongylinae brazileiras, Braz. Med., 28: 163, 183

WAGNer, G., SEITZ, K. A. (1982): Structure and function of the male copulatory apparatus of Pelodera strongyloides (Nematoda, Rhabditidae). Zoomorphology, 97: 121 - 132 WEN, G. Y., CHEN, T. A. (1976): Ultrastructure of the spicules of Pratylenchus penetrans. J. Nematol., 8(1): $69-74$ Wright, K. A. (1978): Structure and function of the male copulatory apparatus of the nematodes Capillaria hepatica and Trichuris muris. Can. J. Zool., 56: $651-662$ 